\title{
The Role of the Creative Industries: Translating Identities on Stages and Visuals
}

ALESSANDRA RIZZO

\section{Abstract}

In the area embracing the creative industries, documentary films, audiovisual narratives, art installations, museum exhibitions, and theatrical performances can be viewed as distinctive artistic genres that focus upon the representation of truth by providing the public with a variety of authentic life stories. These can generate both interesting visual frames and intercultural and cross-cultural encounters, where audiovisual translation modes can become instruments of renarration and knowledge dissemination and transform translation into a tool of (re)creation and transcreation (Katan 2016), while questioning power relations and media discourse.

Keywords: Translation, Interdisciplinary Perspectives, Narrative Theory, Audiovisual Narratives, Transcreation, Relocation, Media Discourse.

\section{Introduction}

Drawing on research on narrative theory (Baker 2006; 2014) in translating and interpreting studies, on the interdisciplinary relationship between translation studies and the visual and performing studies, and on the principal diversities between media discourse representations and aesthetic constructions on the topic of the migration crisis, this study addresses the issue of transferring cultural difference and language diversity in public spaces through the telling of authentic stories from the mouths of migrant people, which contribute to the reversal of anti-refugee media discourses. Against the lens of a political reframing of migrant communities in the arts, translation, in collaboration with the aesthetics of migration (Moslund et al. 2015; Mazzara 2015), 
is scrutinised from a non-mainstream perspective that involves acts of interventionism and resistance, collaboration and solidarity (Baker 2016), adaptation and performance (Krebs 2014, Bigliazzi et al. 2013, Marinetti 2013a, 2013b).

The corpus that is taken into account includes Queens of Syria (by Syrian filmmaker Yasmin Fedda, 2014; by British director Zoe Lafferty, 2016) and Odisseo Arriving Alone (by Iraqi artistic director Yousif Latif Jaralla, theatrical performance, 2016; by Italian artistic director and photographer Gaetano Cipolla, art and photo exhibition, 2016). Attention is also paid to the photo-textual installation project \#RefugeeCameras (by German artist Kevin McElvaney, 2016), which was presented on the occasion of the second edition of the Festival of Migrant Literatures (2016) in Palermo, and on a permanent antimuseum installation Porto $M$ (by the Askavusa Collective, 2013), sited on the island of Lampedusa.

The interdisciplinary perspective, where translation dialogues with the visual and performing arts, and also with adaptation and performance studies, encourages the growth of aesthetic products centred on personal narratives as adaptations to the ancient myth on screen and performances on the stage. Interdisciplinarity, I argue, influences translation mechanisms, where the process of knowledge dissemination produces acts of translations as forms of rewriting, reinvention, reinterpretation and relocation, by means of which intimate experiences are re-interpreted by target audiences who bear witness to human stories converted into myth.

In order to fight back we must connect, we must communicate, we need to learn solidarity, we must translate in more ways than just verbal translation, we must attempt a translation of the streets, a deep translation. Collectively we must move on to somewhere new (Rizk 2013: 237, qtd. in Baker 2016). 
Translation as a mode of communication that favours mediation and exchange between global cultures has considerably expanded and grown in the area of the creative industries. The study of translation has also evolved in its multimodal survey of the ways by means of which words, sounds and images are adapted and re-interpreted within cultural frameworks and digital platforms. Translation has thus remarkably acquired a crucial role in aesthetic discourse as a multimodal tool that involves a variety of fields, such as the visual and performing arts, as spheres belonging to the creative cultural sector.

The interest of scholars, filmmakers and artists in the relevance of translation to the area of creativity has increasingly proliferated with particular regard to the exploration of the modes and genres through which translation can be viewed as an expedient for the re-framing of migrant identities from contexts of crisis in contrast to media stereotypical representations as mere number of deaths and nameless bodies. Contemporary artists' modes of communication through their art provide numerous levels of comprehension of the complex issues surrounding the nature of modern warfare and the continuing state of emergency in which we all live today. While representing contemporary conflict through first- and second-hand experiences, stories narrated through aesthetic discourse offer alternative viewpoints, not always reflected in mainstream media. By "reversing the anti-refugee discourse with art" (Shabi 2016), the creative and cultural industries are willing to translate the real voices of migrant identities by the creation of public spaces, where translation itself appears to be an instrument of connection between artistic and social issues. The ever growing potential of translation in both metaphorical and practical terms is thus strengthened by the spread of artistic narrative forms, where migrant subjectivities can speak 
through the process of transmutation of their identities as subjects of power.

Within the international cultural framework that bears witness to the effects of translation on the growing diffusion of visual and performing artistic forms on the migration crisis, I argue that recent aesthetic narratives of migration are transformed into counter-narratives of dissent and protest, where refugees and migrant people act through modes of "translation as renarration" (Baker 2014). Narratives of personal stories across public platforms open up new challenging procedures of translation as resistance where, as Mona Baker's recent research sheds light on, translation emerges in its political role and encourages "discursive and non-discursive interventions in the political arena" (Baker 2016: 7). Translation considered in both its broad and its narrow sense (ibidem), to borrow Baker's terminology, produces acts that allow different types of activists - artists, scholars, citizens, and migrants - to think about both the challenges and limitations that encompass the phenomenon of translation as a political and social practice.

By looking at the production of artistic narratives of migration not as an end in itself, I also claim that the generation of public stories circulating across artistic circuits has recently contributed to transforming the experiences of the migrants from 'adaptors' and 'performers' on screens and stages into 'intercultural translators'. Stage and screen have turned out to be the favourite locations of translation, and the dynamics of translation, adaptation and performance have produced forms of linguistic hybridisations and cultural blends. To conclude, I argue that translation in its dialogue with adaptation and performance mechanisms has also acquired a significance of transcreation (which goes beyond the literal application of the concept to the area of advertising), from which I borrow its meaning applied to the fields of creativity and innovation. 
Transcreation in the aesthetic narratives of migration gives voice to distant cultural realities and promotes new linguistic forms.

Migrant narratives are presented in a wide corpus of creative genres ranging from documentary films and theatrical pieces to museum exhibitions and photo-textual installations. The corpus functions as a form of translation of the self and bears witness to "performative" acts (i.e. performance and performativity), and to procedures of adaptation as resistance that, as such, act in opposition to domesticating modes of translation. Beginning with a theoretical survey of the interdisciplinary connections between translation and adaptation studies, and the performing and visual arts, attention is afterwards drawn on the role of the creative cultural industries in relation to translation practices as forms of transcreation in host countries. If, on the one hand, the creative process of translation involves the transfer of migrant people's authentic selves on screen and the stage in contexts of arrival, on the other hand, the audience participates in a transcreating process, which consists in the upsetting of migrant identities who, from a swarm of people in media discourse, are converted into individuals in aesthetic forms.

The corpus included in this study are the uncommon display and combination of material objects belonging to migrant 'travellers' has created a space of transcreation in terms of target adaptation and activism. While exploring the traumas the migrants had gone through during the crossing of borders, the artistic interventions as a part of this corpus have turned into forms of translations as adaptation from ancient plays, and into translations in terms of acts of (re)-narration of life experiences on the stage, screen and in museum exhibitions. The advancement in the art of telling stories has encouraged the growth of creative modes of narration, where the concept 
of stories has become crucial to the development of new modalities, functions and all sorts of translation that are contributing to reversing the anti-refugee politics and the media discourse's prevailing interest in the spectacular and sensationalist aspects of the migration crisis.

The four artistic cases in point aim to explore and understand how contemporary migratory movements have come to reshape the role of the creative cultural sectors, and how translation mechanisms have been transformed into collaborative instruments and privileged activities for the dissemination of cultural memory in contemporary societies. The interdisciplinary perspective, where translation dialogues with the visual and performing arts, and also with adaptation and performance studies in their application to the aesthetics of migration, stimulates mechanisms of self-mediation that sensitise citizens to the urgent topic of human migration. The contexts of the migration crisis have stimulated the proliferation of creative forms of unquestionably global translation of personal narratives as adaptations to the ancient myth on screen and performances on the stage. These narratives, conceived as acts of translations, imply processes of rewriting, reinvention, reinterpretation and relocation, which construct translation not in terms of binary oppositions, where creative freedom acts against linguistic confinement, or piracy against faithfulness, instead, as a transcreating 'movement' by means of which intimate experiences are re-interpreted by target audiences who bear witness to human stories converted into myth.

It is by means of audiovisual translation that the protagonists of the new mythological stories can resist linguistic domestication, while maintaining the opportunity to adapt their experiences to ancient texts and producing original performances that can have international diffusion. Indeed, the 
denial of the traditional notion of translating stories in English lingua franca imposes the "foreignness of the language" on the stage or screen, and also stimulates the spectators to a sort of displacement from the "familiarity of the canonical text" (Marinetti 2013a: 35), and to a type of intercultural negotiation that occurs thanks to the intervention of English subtitles and surtitles. The non-acceptance of English lingua franca implies a "refusal of translation" in terms of assimilation into the target culture. As a result, the act of resistance gives birth to a transcreational act that resides in the transformation of an original product (the ancient plays) from the perspective of the actors in host countries. At the same time, the filter of audiovisual translation modes provides the target audience with new versions of transcreated mythological sources. On some occasions, as cultural texts integrated into the performance, the surtitles in Queens of Syria are transformed into "creative tools", which add new meanings and readings that can be "generated through the different sign systems at work in the performance" (Laudocer 2013: 352).

It goes without saying that in contexts of crisis translation has acquired a powerful political significance, which also involves the preservation of migrants' cultural memory. In Queens of Syria and Odisseo Arriving Alone, migrant people act as political translators and their performing settings are physically and metaphorically the locations where the ancient myth is revisited, re-narrated into 'human' words across geographical spaces and translating decisions are taken. Baker defines "translational choices not merely as local linguistic challenges but also as contributing directly to the narratives that shape our social world" (Baker 2007: 157). The framing and reframing of things, people and events, the act of naming, renaming and labelling objects and facts, intervene in the deconstruction of universal rules and are instrumental in the process of 
negotiation and reconstruction of predefined concepts, ideas and perceptions. The act of translating protest through a variety of narratives of dissent (Baker 2016) - which can range from literary works and traditional folk tales to individual and collective stories, films, press and digital texts, to list but a few - is thus implicitly an instrument that limits and reduces dominant powers, and also reinforces resistance via translatological means within aesthetic discourse: the "interplay between dominance and resistance allows us to elaborate a more complex picture of the positioning of translators and to embed them in concrete political reality" (Baker 2007: 167).

\section{Interdisciplinary Perspectives and Translation}

The role of translation in shaping contexts of protest occupies interdisciplinary spaces that range from the visual arts and narrative theory in translation studies to adaptation and performance studies. The dialogue between translation studies and the visual arts is reinforced by strategies of adaptation and performance in translation practices, which encourage scholars to venture into territories that can give voice to innovative discoveries. Translation is thus considered in relation to adaptation and performance as a technique and mode through which migrant experiences can be transferred into artistic and creative forms. This allows the re-articulation or a rethinking of the interdisciplinary relations between translation and other sectors in the humanities. In particular, in this study where migrant narratives have a leading role, the social dimension of translation and the performative nature of cultures are brought to the fore as productive ways of studying translation as a performative and linguistic practice.

The perspective of adaptation that is taken into account arises and develops in contrast to the standard concept of adaptation 
as manipulation, and fosters, instead, the production and diffusion of migrant narratives on the stage and screen, where native languages (i.e. Arabic or African dialects) and cultures (i.e. Arab and African customs and everyday habits) are preserved, and translation as adaptation within the artistic sector becomes an act of resistance. Meanwhile, the use of audiovisual translation modes involves the angle of the internationalisation of migrant narratives as stimuli for community involvement, solidarity and collaboration in the aesthetic promotion of predominantly visual narratives (i.e. text-objects, photo-texts in museums and installations) and visual-textual narratives (i.e. documentaries and theatrical performances) against mainstream media diffusion. This opens up thoughts about how appropriate representation is, how faithful and transparent the relation between depiction and reality is, not simply measuring these aspects, but through the revelation of the historical power of films, videos, arts, and, within them, of theatrical performances, sculptures, paintings, drawings, installations, and of a variety of artistic forms, by means of which cultures, languages and modes of expression are seen to be in conversation.

Moving from the position according to which translating migration through the arts is a significant challenge to the preservation of stereotypes and an instrument through which it is possible to deconstruct prejudices and cross socio-political boundaries, the starting point of this survey is Sandro Mezzadra's definition of migration as a "fait social total" (Mezzadra 2005: 794), which deserves to be explored not only through the canonised lens of scholarly disciplines, but also by means of narration and everyday visualisation of images. Accordingly, artistic practices can become active forms of expression of 'travelling' migrant cultures, interested in the production of wandering texts and travelling objects. It is 
against this framework, where the visual arts engage in dialogue with translation and migration studies, that a larger theoretical universe, including narrative theory, audiovisual translation studies, adaptation and performance studies, can become collaborative and supportive methods of research.

Against the concept of culture as a "text", as understood in Clifford Geertz's terms, or in Jurij M. Lotman and Boris A. Uspensky's semiotic system (1978), the interpretation of art as event, which was rooted in the 1960s, has grown during the years and encouraged the understanding of culture as performance and stimulated the development of an "aesthetics of performativity" (Schechner 2002: 21), mostly based on "the physical co-presence of actors and audience" (Fischer-Lichte 2004, qtd. in Bigliazzi 2013 et al.: 1), and on the dynamic response between the parts. From this viewpoint, the act of translating migrant stories can be looked at "as performance and in performance", which "implies a dynamic process of (re)signification integrated with the overall event in its various phases of production" (Bigliazzi et al. 2013: 2). In the relationship between translation and performance, the actors become translators who, as cultural promoters, blur the boundaries between translation, adaptation and performance within the category of "cultural (re)creation of meaning(s)" (ibidem).

Oral narratives (stories from the migrants) and written texts (ancient plays) are translated from a double perspective: on the one hand, translation involves a linguistic transfer from an oral verbal experience into a written verbal one and, on the other hand, translation regards the adaptation of verbal experiences into performing acts. These translating mechanisms are connected with and dependent on the principles of narrative theory, where the telling of stories is pivotal to human communication and interaction. Accordingly, scholarly 
research on translation has confirmed a wide interest in favour of the "exuberance of the performance and of the performance (as text)", where the field of the translator has slowly "shifted from the verbal to the polysystemic and culturally determined semiotic event, opening up areas of investigation concerning the relationship between text and performance, translators and directors, and the co-participation of audiences" (ibid.: 2). It goes without saying that the performative turn has influenced translation studies and also given centrality to translation as both a linguistic and a performative act to be viewed as a specific activity on the stage and in everyday narratives. Similarly, Katja Krebs, who has significantly contributed to investigating the areas of Translation and Adaptation Studies, claims that translation and adaptation - as both practices and products - are an integral and intrinsic part of our global and local political and cultural experiences, activities and agendas. Translation is pivotal to our understanding of ideologies, politics as well as cultures, as it is simultaneously constructed and reflects positions taken. Similarly, adaptation offers insights into, as well as helps to establish, cultural and political hegemonies" (2014: 1).

The spaces of translation, interpreting and subtitling within the political dissemination of migrant stories across artistic productions, while covering a range of modalities and types of interaction, themes and questions arising out of the concrete experiences of activist artists (i.e. McElvaney; the Askavusa Collective), can be regarded as concrete tools of mediation and interaction that support the migrants in their positioning as full participants within the political debate. A variety of theoretical approaches can help investigate the political framework and the cultural and linguistic features of a migrant story in its process of circulation as a form of (re)-narration of memories, 
past experiences and present expectations across open spaces and digital platforms.

According to Baker's narrative theory (2006) in Translation and Interpreting Studies, narratives have social existences and, as such, can be disseminated as forms of knowledge across mainstream and popular cultural circuits and digitalised systems, through a wide range of translational practices. Functional approaches in translation studies, such as Christiane Nord's focus on the communicative event (1997), register and language users, and Gunther Kress's and Theo van Leeuwen's multimodal discourse analysis (2001), encourage the investigation of language use in self-mediated narratives and, at the same time, contribute to dismantling the strategies of oversimplification, manipulation and omission which the language of news stories is based on. While building networks of solidarity and collaboration across linguacultural, national and international boundaries, translational activism reverses power structures and, by means of translation, migrant stories are likely to be shaped by interventionist mechanisms, and to exploit multimodal expedients as instruments of resistance to mainstream modalities of transmission of knowledge.

The dialogue of translation with other disciplines reinforces its social and cultural dimension. The interdisciplinary aspect of translation (Pym 1998) fosters intellectual development and allows new lines of communication between translation and adaptation studies, whose encounter, in turn, strengthens the relationship between translation and the visual and performing arts. The openness of translation studies endows it with the status of an autonomous discipline (Holmes 1972, SnellHornby 1992), but also that of an "interdiscipline" (Pym 1998) in the way in which it deals with the visual and performing arts in metaphorical and practical terms. 
In these interdisciplinary connections, the role that translation has taken as "a means of negotiation of cultural contact in theatre practice" and, in particular, as "a site for the construction and dissemination of images of foreignness and otherness" (Marinetti 2013b: 309), has acquired challenging results. The challenge derives from the fact that such a relationship goes beyond the process of translating personal narratives to the adaptation of dramatic texts. It also entails everyday translating and interpreting procedures in multicultural events and contexts of crisis (e.g. refugee camps), as well as in multimodal media settings, where an increased number of artistic productions in foreign language are required to circulate across networked platforms through surtitles and subtitles, and interpreting as cultural mediation. The relationship between translation and performance, translation and adaptation, and translation and the visual arts, is therefore based on the localisation of translation at the meeting point of a plurality of textual productions (oral and written) and their reproductions, which echoes what André Lefevere identified in terms of "rewriting" as functioning in a given society and in a given way (1992: ix).

Artistic forms become models of translation, which involve a socially governed activity, or actions as performances, which permit cultures and cultural phenomena to be known and understood as participative and 'in performance'. Queens of Syria and Odisseo Arriving Alone, as types of translations of personal experiences and sufferings performed on the stage and screen, are adapted from ancient texts. These translations become performative, to put it in Richard Schechner's terms, since they involve a process according to which cultural signs are not mediated but transmitted through mechanisms of construction "in action, interaction and relation" (Schechner 2002: 24). Indeed, what marks the significance of the 
relationship between the visual and performing arts and translation is the advantage that the concept of translation as performativity implies. It places originals and translations, source and target texts, dramatic texts and performances on the same cline, where what counts is no more the degree of distance from an ontological original but the effect that the reconfigured text (as performance) has on the receiving culture and its networks of transmission and reception (Marinetti 2013b: 302).

The adaptation and performance procedures applied to the artistic products under scrutiny therefore result in the transference of originals into translations that have different contexts and modes of expression and construction. Indeed, the countries of departure, in the form of translations into the visual arts, are embedded in extensive socio-political dissatisfaction, economic uncertainty and large-scale migration. As such, contexts of origin conveyed in aesthetic discourse within a European artistic framework have given rise to collective experiences of conflict and dislocation. These have assumed new roles based on empowerment and emancipation, endowing translation with a dynamic vein of creativity and artistic interest in dealing with settings of crisis. In the performative turn in cultural studies towards aesthetics of performativity, Richard Schechner claims that "during the last third of the twentieth century", the world changed its configuration and "no longer appeared as a book to be read but as a performance to participate in". In the specific cases of Queens of Syria and Odisseo Arriving Alone, "translation as performance and in performance" (Bigliazzi et al. 2013: 320) becomes a form of "meaning-making" and implies a dynamic process of re-signification. The two works, if we consider them from Cristina Marinetti's assumptions, imply acts of performance and performativity, since they transform existing 
"regimes of signification" (Marinetti 2013b: 320).

\section{Against the Media}

In the articulation of subjective experiences in native idioms or European languages that attempt to reverse the misrepresenting and often offensive media language in informing about the massive influxes of people who abandon their own countries to find a life in Europe, Kevin McElvaney's opening description of his project \#RefugeeCameras (2015, online) explains the reasons that persuaded him to create his artistic work:

The refugee "crisis" appears in the media everyday

Every day I saw almost the same pictures

It always frustrated me

As a photographer I asked myself:

Can I photograph this in a different way?

Will I see exactly this when I am there by myself?

Does the coverage miss something or has the wrong focus?

[...]

We always decide what is important to say and what is not

We always photograph the refugee in their situations

We are those who tell the stories

We

[...]

Let's try to give the refugees a voice

Let's try to let them decide what is important to say and what is not

Let us see the individual behind the anonymous concept of a "refugee"

Let photography be the medium for this. (2015, online)

Refugee voices portray the "endless motion" that critics and scholars have defined as surrounding and pervading "almost all aspects of contemporary society" (Papastergiadis 2000: 1). This mechanism favours "social encounters and change" and promotes "new aesthetic and cultural phenomena" (Moslund et 
al. 2015: 1). The role of the arts in dealing with the lives of migrant people is therefore, on the one hand, to spread new information or forms of knowledge about distant cultures and, on the other, to shape identities and reveal how politics and societies act in the specific contexts of crisis.

In this regard, Federica Mazzara critiques media discourse on the representation of the "real actors of the Mediterranean passage" as an "unnamed and anonymous mass of people" (Mazzara 2015: 449), while putting emphasis on the fact that media discourse bases its breaking news on "normative and conventional formulae that allow a recognition and a passive acceptance of certain patterns, considered trustworthy because of their institutionalized status" (ibid. 451). In such a context, the "realm of aesthetics" intervenes in the act of giving back migrant people names and a certain degree of "visibility" to potentially transform them into "subjects of power" (ibidem).

British news media are prone to overuse nominalised terms as descriptive and connotative of a determinate typology of people, clearly highly discriminating, such as migrants, refugees, asylum seekers, exiled, illegal aliens, illegal migrants, illegal immigrants, economic migrants, and bogus. The interest is obviously oriented to what their general condition is, but no attention is paid to their personal stories, cultural interests, competences and duties. The terminology used in the media is often linguistically dehumanising and distancing and, certainly, bluntly pejorative. In reaction to David Cameron's way of addressing migrant people as a "bunch of migrants" in the BBC news, a video with interviews from the Help Refugee Association has asked "some of the refugees in Calais what they did for a living before their lives had turned upside down."

${ }^{1}$ This interview was produced by the Help Refugees Association (2016). 
In opposition to the offensive expressions occurring in the media, the refugees at Calais have revealed their job activities in the countries of origin. From the video display, it was possible to read words such as "butchers", "painters" and "drivers" to "translators", "software computer programmers" and "footballers", from "writers" and "carpenters" to "clinical nurses" (Sommers 2016, online), and many other business activities. It was on the $2^{\text {nd }}$ of January 2016 that the British left wing criticised Cameron's phrase, when Labour MP Yvette Cooper indicated that Cameron's language was "not appropriate" or "statesmanlike", especially with regard to such a "complex and sensitive" issue (BBC news 2016: online). Similarly, shadow minister Kate Green put Cameron's expression in the lexical category of "offensive, hurtful and divisive" (ibidem) terms.

\section{The Corpus}

Queens of Syria and Odisseo Arriving Alone are inspired by the heroic tales in the Trojan Women and Odyssey respectively and consist of adaptations of the ancient texts to migrants' accounts on screen and stage. The audiovisual translating devices offer variants or simplified versions of the Arabic and multilingual spoken narratives, since the target audience may be unfamiliar with the source language narratives. The two works present cases in which "interlingual translation does not only occur in the dramatic text but in the performance itself" (Marinetti 2013b: 314), and where a performative understanding of translation involves productive transformations at the level of target reception. In Queens of Syria and Odisseo arriving alone, the Syrian refugee women living in Jordan and the African migrants living in Sicily reflect upon their experiences before and after fleeing from their home countries, the passage across international boundaries and the Mediterranean Sea, and upon the condition 
of living in territories as illegal foreigners. Original times and places in the ancient works are necessarily shifted into new ages and locations. This recalls David Lane's thoughts of the concept of re-contextualisation as a form of adaptation, which he defines "as the act of taking an existing book, play text or screenplay and transposing it to another context" (Lane 2010: 157). By redisplaying Greek myths alongside contemporary experiences of migration, truths and human stories are reactivated and reshaped, rewritten and relocated.

\section{Queens of Syria}

As a theatrical performance and documentary film, Queens of Syria has a long history of rewriting rooted in screen and stage belonging to the same wide artistic project "Developing artists present Refuge Productions", divided into different parts. First staged in Amman in 2013 with Syrian director Omar Abusaada, the work was then adapted to the visual arts and transformed into a documentary film by Syrian filmmaker Yasmin Fedda in 2014, eventually culminating in a UK tour on stage directed by Zoe Lafferty in 2016.

On the occasion of the UK theatre tour, "Refuge Productions" brought thirteen Syrian refugee women living in Jordan to the UK in order to adapt an Arabic performance of Euripides's anti-war tragedy, The Trojan Women: "They are the voiceless voiced. This is made clear from the opening moments when they clap their hands over their mouths, then shout, in unison, lines from Euripides' fierce tragedy The Trojan Women" (Bano 2016: online). These women had never acted before. Written against the cruel Athenian repression of the independent island of Melos and set during the fall of Troy, the play explores the uncertain future of the Trojan women, while contemplating a life of exile and slavery. The Syrian women were astonished by the parallels to their own real life 
experiences and could not but identify their existences with the female characters' fate, as depicted in the tragedy. In spite of the numerous problems the Syrian actresses faced, the women were a unified group, encouraged by the discovery of new voices bringing their untold stories to a global audience who wanted to listen to their narratives of loss and exile.

Three years after the first stage production, "Developing Artists", together with "Refuge Productions", thus rewrote a new version in Jordan, directed by Zoe Lafferty, which led to the UK national tour. Unprotected stories, made inaccessible due to conflict, occupation and censorship, are again central topics in Queens of Syria UK Theatre Tour, which is the latest from the "Syria Trojan Women Project". It opened at the Young Vic on the 5th of July, following a four-week workshop in Jordan. The cast toured Brighton, Oxford, Liverpool, Leeds, Edinburgh and Durham, and concluded in the London West End. The story has as its protagonists a group of Syrian women, female refugees who, distant from their husbands, exiled in Jordan and created an extraordinary modern retelling of The Trojan Women. As in the documentary film, the women scrutinise parallels on stage between the ancient Greek tragedy and today's civil war in Syria.

Both the project and performance represented a life-changing opportunity for the refugee women themselves, and also an authentic experience for British audiences who heard about the harsh realities of life from the mouths of refugees. In terms of translation, the first-hand transmission of Syrian knowledge takes place by physically transferring the actresses from a Jordanian stage to a British one and also by using the original Arabic language on the stage while transferring it into English surtitles. The narrative level intersects with the dimension of translation as adaptation in performance, where an all-female cast of Syrian refugees combines the women's own narratives 
of war and exile in Syria with the ancient Greek stories.

In 2014, Syrian filmmaker Yasmin Fedda had already produced a documentary version of Queens of Syria, which the artist described as a documentary about a drama theatre workshop that also took place in Jordan. What is shown in the documentary is a group of almost sixty women involved in creative workshops to put on a play, where they would interpret and adapt The Trojan Women to their own stories. As a form of adaptation based on providing the public with a 'transcreated' version of the crisis in Syria from a mythological perspective, the documentary contains audiovisual translation modes that are used as cultural texts that summarise the actresses' monologues, where the past contrasts with a sad and painful present. Mythological stories are transcreated and transformed into narratives of sorrow and homesickness:

\begin{tabular}{|l|l|}
\hline Subtitle 1 & $\begin{array}{l}\text { You are living a painful present while your soul } \\
\text { yearns for a happy past. }\end{array}$ \\
\hline Subtitle 2 & This part of the play makes me cry a lot. \\
\hline Subtitle 3 & $\begin{array}{l}\text { We left our home town, } \\
\text { There was a lot of shelling. }\end{array}$ \\
\hline Subtitle 4 & I want to find a better life for my children. \\
\hline Subtitle 5 & The play talks about something real to us. \\
\hline Subtitle 6 & It's old, but history repeats itself. \\
\hline
\end{tabular}

Table 1

Queens of Syria on stage opens with a chorus recalling the ancient chorus. The Arab women act in Arabic and their gestures and movements on the stage relocate the audience into an Arab context, where the effect created by the chorus itself is innovative. The English surtitles allow the public to follow the stage play, even though the audience's attention is often concentrated on the acting itself rather than on the reading of the visual texts. In fact, in some cases, the actresses' gestures vigorously support the meaning of the written texts. This 
feature in the performing act creates an ideal harmony between the visual cultural expansion applied to the surtitles and the process of acting on the stage. In one of her numerous monologues, the Arab woman/actress, Fatemeh, depicts her everyday life in Syria and brings to mind the scent of the flowers and the heat of the sun warming the window in her Syrian home. The surtitles and the woman's gestures in the performance evoke a feeling of inebriation symbolising the perfume of the flowers and also stressing the physical benefits that originate from such a sensory pleasure. Troy is turned into any Syrian city persecuted by war, whereas the Trojan women are transformed into Syrian wives forced to exile and solitude. The chorus can be read through the surtitles, which scroll on the left and right sides of the stage:

First Chorus: Troy is but a smoking city; it has been sacked by the Argive spear. The sacred groves are desolate and the sanctuaries of gods are awash with blood. Gold and Trojan spoils are being sent to the ships of the Achaeans. They are waiting for a fair wind to blow from the stern, so that they can have the joy of looking up on their wives and children. Scamander echoes with many a howl from female captives as they are allocated their masters. But all Trojan women who have not been allocated are in these tents. They have been picked out for the foremost men of the army.

Euripides's classical work is the first play having a female point of view following a war, containing no signs of acts of revenge. Therefore, the play contextualises the stories of people who had fled from their homes and come to another country trying to deal pacifically with any sort of repercussion. The very beginning of the Chorus' words, "Troy is but a smoking city", suggests the image of Syria as a burning country, and Aleppo as a city in flames. The portrayal of the high number of women and children exiled and abandoned in 
refugee camps is adapted to the Chorus' statements, such as in "all Trojan women who have not been allocated are in these tents".

On screen, the process of translation as adaptation is also constant. In the following subtitles, one of the actresses tells about her life by means of comparison of her own happy existence to that of Hecuba in the ancient Trojan world.

\begin{tabular}{|l|l|}
\hline Subtitle 1 & Hecuba is just like me. \\
\hline Subtitle 2 & She was the wife of the King of Troy. \\
\hline Subtitle 3 & Then she lost everything she owned. \\
\hline Subtitle 4 & She lost loved ones and family. \\
\hline Subtitle 5 & It's like us, she was a queen in her home. \\
\hline Subtitle 6 & I met with other Syrian women. \\
\hline Subtitle 7 & Each one is learning about the life of the others. \\
\hline Subtitle 8 & This isn't our home. This isn't our country. \\
\hline
\end{tabular}

Table 2

Similarly, the actresses on the stage have their own voice and tell stories about their countries and abandoned homes. In Fatemeh's words, Syria was not what the war had transformed it into:

Fatemeh: Syria is my country and Homs is my beautiful city that has all my cherished memories. My warm house is full of memories of love that have stayed with me all the time. I could not, and I will never forget it. In my house everything is beautiful and the most pleasing thing about it is my small window where I receive the sunlight every morning and I breathe from it (everyone takes a breath), the scent of jasmine; my old country's smell roses and basil.

Surtitles are not only a vital part in the performance, but also intensify the cultural message of the play by creating a literary and textual connection with the mythological narrative. Audiovisual translation devices fortify the union between the heroic tales in the ancient plays and the same heroic stories of 
conflict, persecution and displacement in contemporary migration.

\section{Odisseo Arriving Alone}

Odisseo Arriving Alone, a stage play that took place in December 2016 is also a museum exhibition arising from the commitment of a scholarly artistic group rooted in the Itastra centre in Palermo. The play is the dramatization on stage of African memories belonging to the experiences of unaccompanied minors who crossed the Mediterranean Sea to reach the Sicilian coasts in search of a life. As in Queens of Syria, the characters of Odisseo - mainly African men - are inspired by the stories of the ancient world and, in particular, by the reading, interpretation and adaptation of the Odyssey. The stories of Nausicaa and Polyphemus, Calypso and Telemachus, the island of Phaeacia, and the Cyclops have been translated into various African languages - ranging from bambara, wolof, bangla and pular to English, French, Arabic, and Polish. The process of translation as adaptation from the Homeric narrations of the migrants' journeys across passages of danger and desperation to their mother tongues has given birth to a multilingual African stage in Sicily. This polyphony of voices and languages has made the theatre a place where languages become a location of encounters, and where migrant stories can be learned, shared and amplified.

Beyond the words, the young actors translate their experiences into the arts and, in particular, they draw and paint the beginning of their journeys from the countries of origin to the places of arrival. The creative workshop has reached its climax in the production of a variety of visual forms that have embraced feelings of frustration and desperation, happiness and joy, memory and sadness, past and future. These artistic experiments can be viewed as translations of emotions, 
visually performed in the creation of an installation that takes the same name as the theatrical performance, Odisseo Arriving Alone. In this installation, the characters narrate Odysseus's return journey and his sea adventure when, after leaving the island of Calypso, he was caught by a storm that destroyed the raft on which he was travelling. This journey - which translates the migrants' passage - is told in two canvases ( $L e$ tele di Penelope, 2016), which are composed of paper strips, where the African migrants' thoughts are visualised through the depiction of their sensations that are based on the natural alternation of happy and tragic moments in life. The experiment has given birth to an intersection of multilingual translations transferred into the visual arts (i.e. videos, drawings, self-portraits, and sculptures, whose case in point appears below).

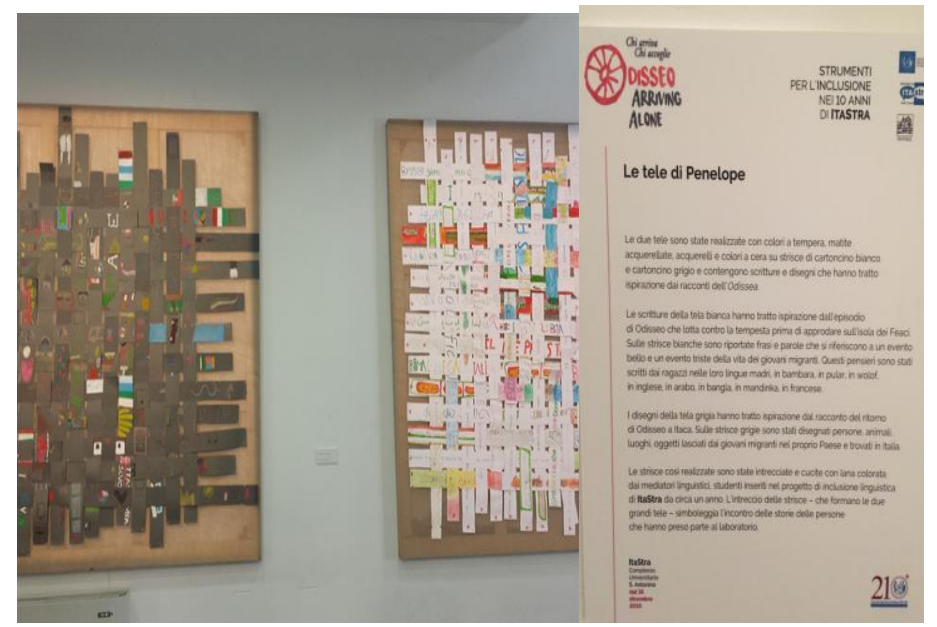

Porto M

Resistance through language, translation and visual display takes place in Porto $M$, which is an anti-institutional social museum sited on the island of Lampedusa and created by the Askavusa Collective in 2013. It aims to challenge mainstream 
institutions by producing counter-narratives that depict the lives of the migrants before and after their passage across the Mediterranean. The museum is chiefly conceived as an antimuseum, containing no labels or panels, where the display of everyday objects belonging to the migrants reflects and reproduces their material culture, which is rendered all the more immediate because of the routine nature of the items. This typology of "museum translation" provides visitors with first-hand experiences and knowledge, offering a radical perspective on migration beyond mere narratives and rhetorical forms, where identities are adapted to a non-standard museum display and performed through minimalist details. Porto $M$ is also on a digital platform that is supported by activist amateur subtitlers and interpreters who attempt to favour emerging agents of political intervention in public life and the transnational flow of self-mediated textualities.

The museum testifies to the growth of alternative repertoires of action in public and private spaces, where migration is narrated in terms of material culture in contrast to modalities that have amplified scepticism in traditional procedures of political behaviour and patronising forms in mainstream media. In Porto $M$, the material objects that are the property of the migrants, such as pans, medicines, boots, knifes and forks, sacred books, water containers, trousers, and videotapes, are exhibited with no labels and panels with the aim to translate into the visual arts the migrants' existences from an everyday perspective but, at the same time, by stressing their efforts in the sea passage. Here are some cases of museum translation applied to the rendering of the migrants' material cultures: 
The Role of the Creative Industries...
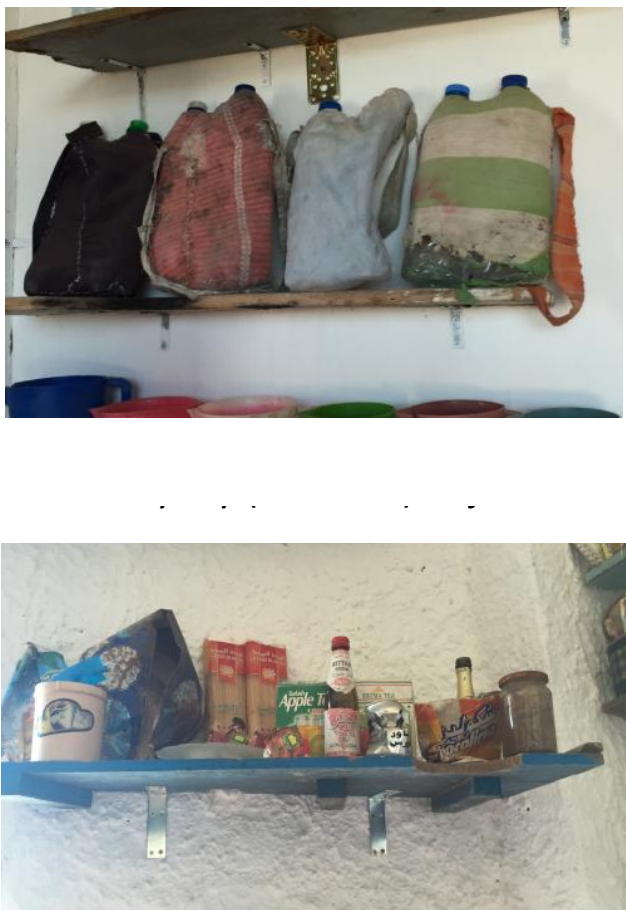

Everyday (Material) Objects

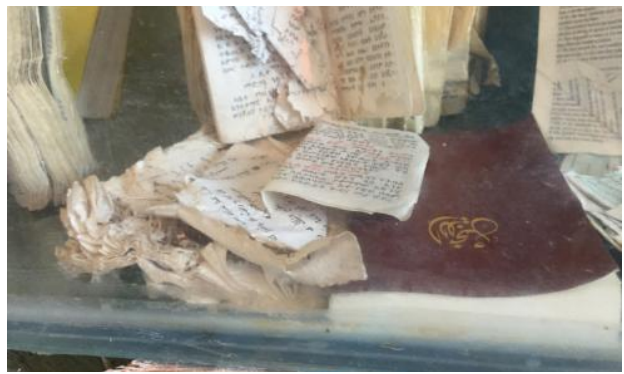

Sacred Books and Letters 


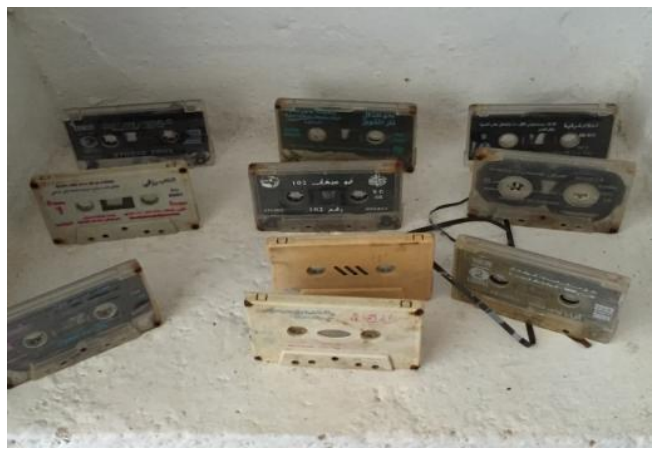

Project \#RefugeeCameras

Kevin McElvaney's project \#RefugeeCameras started in December 2015. In this visual project, the artist gave singleuse cameras to refugees he met in Izmir, Lesbos, Athens and Idomeni. Three months later, seven out of fifteen cameras came back in their prepared envelopes. In 2016, this project became an artistic photo-textual installation, composed of pictures and short narratives produced in the language of each migrant and, some of them, also containing their English translations made by the migrants themselves. Texts and images tell the stories and experiences of migration belonging to people from different contexts of crisis. Translation can be viewed in the act of performing identities in the acceptance of taking pictures in order to auto-translate persecution and exile. As shown below, each photo is accompanied by textual explanations. The first installation of project \#RefugeeCameras in Palermo was based on the display of intersected pictures to represent a mixture of a variety of migrant experiences and ethnical groups. The photographic and textual exhibition, on the one hand, captures the state of desperation of these traumatic journeys and, on the other hand, puts emphasis on situations of hope, joy and relief, which bear witness to "the individual behind the anonymous concept of a 'refugee"'. 
The Role of the Creative Industries...
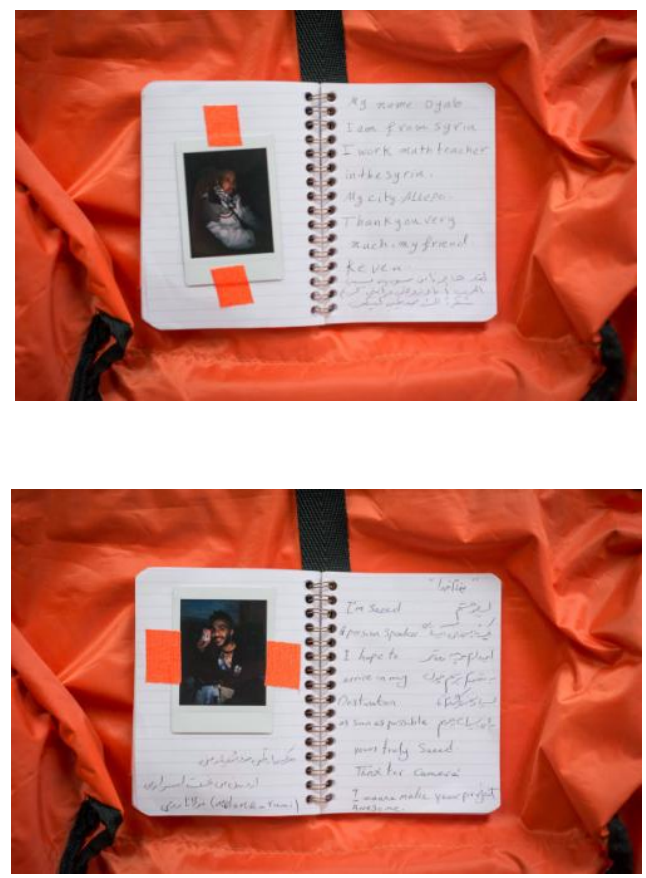

In the light of the multivalent nature of translation, the circulation of migrant stories through the arts involves the dissemination of knowledge that encourages the relationship between materiality (i.e. the artist's performances, the objects in the installations/exhibitions) and translation (the process itself of transferring cultures into aesthetic forms). Having an impact on aesthetic or socio-political changes, the act of reclaiming public and digital spaces in search of antiinstitutional agendas, therefore, generates collaboration and contributes to assembling an audience of emotional receptivity (Silverman 2015).

\section{Concluding Remarks}

The socio-political perspective of translation in the visual arts and the advanced communication technologies are highly 
effective in representing new movements of protest and dissent, and also testify to a radical developmental change in the identity of people who, from a "rather passive informational citizenry" come to be a "rights-based, monitorial and voluntarist citizenry" (Schudson 1995: 27). Movements of "dominance and resistance" (Baker 2007) are routed into forms of contemporary storytelling, which are given voice in textual and visual narratives, such as stories, interviews, documentaries, paintings, and video diaries. These have become re-enactments and re-creations of stories that can be told from varied angles and re-narrated across diverse immigrant communities, social contexts and platforms, and from mother tongues or non-standard English into standard European languages. In Queens of Syria and Odisseo Arriving Alone, the linguistic transfer from Arabic and African languages into English takes place through the audiovisual modes of subtitling and surtitling, or, in some cases, such as in Odisseo Arriving Alone, translation does not occur at all. In Project\#Refugee Cameras, the process of translation happens in terms of auto-translation, whereas in Porto $M$, the museum curators do not translate and label objects. Language mediation and non-translation systems are used as expedients to re-frame acts of protest and dissent in a globalised world. From the perspective of networks and social groups centred on principles of non-hierarchy and pluralism, cross-language and cross-cultural negotiations, and different forms of mediation that intervene within aesthetic discourse, have given voice to a multitude of people who previously had no voice.

In the creative cultural industries, translation as a means to construct migrant identities has acquired a multivalent nature that consists of different characterizing roles. These regard a variety of views on translation as a form of interpretation (involving the process of "explaining or making of one thing in 
the language of the other" (Philips et al. 2010, qtd. in Silverman 2015: 4), as a type of transformation (implying "revision, alteration, adaptation, appropriation, repurposing" (ibidem), as an act of displacement (regarding ways of "deand re-contextualization" (ibidem), as a model of transcreation (suggesting, on the one hand, a form of "nourishment from the local sources" (Vieira 1994: 70, 1999), based on the act of devouring ancient mythological stories, and, on the other hand, implying the comprehension of the foreign "in relation to the familiar, which is at the heart of not just mediation but also understanding itself" (Katan 2016: 376), and, finally, as an expression of agency (acknowledging "the power and presence of the object of translation itself" [Philips et al. 2010, qtd. in Silverman 2015: 4). Its multivalent function in the creative sector has rendered translation a collaborative process for the dissemination of knowledge in public spaces and for the visibility of lost identities in contemporary communities, and from places belonging to war zones.

\section{References}

BAKER, M. 2006. Translation and Conflict: A Narrative Account. London \& New York: Routledge.

BAKER, M. 2007. Reframing Conflict in Translation. Social Semiotics, 17(2). 151-169.

BAKER, M.; and PÉREZ-GonZÁleZ, L. 2011. "Translation and Interpreting" in J. Simposon (ed.) The Routledge Handbook of Applied Linguistics. London \& New York: Routledge. 39-72.

BAKER, M. 2014. Translation as Re-narration in J. House (ed.)

Translation: A Multidisciplinary Approach, New York: Palgrave Macmillan. 158-177.

BAKER, M. 2016. "Beyond the Spectacle: Translation and

Solidarity in Contemporary Protest Movements" in Mona Baker (ed.) Translating Dissent: Voices From and With the Egyptian Revolution. London \& New York: Routledge. 1-18. 
BBC news. "PMQs: Labour attacks PM's "Bunch of Migrants" 27 January. Available at <http://www.bbc.com/news/ukpolitics-35419090> (last access 13 November 2017).

BANO, T. 2016. "Queens of Syria Review at Young Vic, London - "the voiceless voiced"” 7 July. Available at https://www.thestage.co.uk/reviews/2016/queens-of-syriareview-at-young-vic-london/ (last access 13 November 2017). BigliazZI, S.; Kofler, P.; and Ambrosi P. (ed.) 2013. Theatre Translation in Performance. London \& New York: Routledge. FISCHER-LichTE, E. 2004. Ästhetik des Performativen. Frankfiurt and Main, Suhrkamp.

GeERTZ, C. 1973. The Interpretation of Cultures: Selected Essays. New York: Basic.

Holmes, J. S. 1972. The Name and Nature of Translation Studies in Translation Section of the Third International Congress of Applied Linguistics. August 21-26. Copenhagen. 66-79.

KatAN, D. 2016. Translation at the Cross-roads: Time for the Transcreational Turn? Perspectives: Studies in Translatology. 24(3). 365-381.

KREBS, K. 2014. Translation and Adaptation in Theatre and Film. London \& New York: Routledge.

KRESS, G. R.; VAN LEEUWEN, T. 2001. Multimodal Discourse: The Modes and Media of Communication. London: Hodder Arnold Publications.

LANE, D. 2010. Contemporary British Drama. Edinburgh: Edinburgh University Press.

LAUdOCER, L. 2013. Exploring a Bilingual Aesthetics in Through Translation in Performance in Bigliazzi, S.; Kofler, P.; and Ambrosi P. (ed.) Theatre Translation in Performance. London and New York: Routledge. 111-129.

Lotman, J. M.; UsPensky, B.A. 1978 [1971]. On the Semiotic Mechanisms of Culture in New Literary History 9 (2). 211232.

MARINETTI, C. 2013a. Transnational, Multilingual, and Postdramatic: Rethinking the Location of Translation in 
Contemporary Theatre in Bigliazzi, S.; Kofler, P.; and Ambrosi P. (ed.). Theatre Translation in Performance. London and New York: Routledge. 27-37.

MARINETTI, C. 2013b. Translation and Theatre: From Performance to Performativity. Target 24 (3). 307-320.

MAZZARA, F. 2015. Spaces of Visibility for the Migrants of Lampedusa: The Counter Narrative of the Aesthetic Discourse in Italian Studies 70 (4). 449-464.

MEZZADRA, S. 2005. Lo sguardo dell'autonomia/Der Blick der Autonomie in Kölnischer Kunstverein et al. Projekt Migration. Cologne: DuMont. 794-795.

NORD, C. 1997. Translation as a Purposeful Activity: Functional Approaches. London and New York: Routledge.

MosLund, S. P. 2015. Introduction in S. P. Mouslund et al. (ed.) The Culture of Migration: Politics, Aesthetics and Histories. London \& New York: I.B. Taurius \& Co. 1-26.

PAPASTERgIADIS, N. 2000. The Turbulence of Migration: Globalization, Deterritorialization and Hybridity. Cambridge: Polity Press.

PhILliPS, R. B. ET AL. 2010. On Materiality and Cultural Translation Available

http://www.materialworldblog.com/2010/07/report-onmateriality-and-cultural-translation/ (last access 13 November).

PyM, A. 1998. Method in Translation History. Manchester: St. Jerome Publishing.

RizK, P. 2013. Interview with Philip Rizk by Shuruq Harb in Art Territories, 20 May. Available at www.artterritories.net/?page_id=2997 (last access 1 February 2015).

SCHECHNER, R. 2002, Performance Studies. An Introduction, London and New York, Routledge.

Schudson, M. 1995. The Power of News, Cambridge, Harvard University Press. 
SHABI, R. 2016. Reversing the Anti-refugee Discourse with Art. Available

http://www.aljazeera.com/indepth/opinion/2016/11/reversinganti-refugee-discourse-art-161101085549043.html (last access 13 November 2017).

Silverman, R. A. 2015. Museum as a Process: Translating Global and Local Knowledges. New York: Routledge.

SNELl-HornBY, M.; PÖCHHACKER, F. and KAINDL, K. (ed.). 1992. Translation Studies: An Interdiscpline: Selected Papers from the Translation Studies Congress, Vienna, Amsterdam. John Benjamins.

SommERS, J. 2016. Refugees in Calais Explain to David Cameron why they are not just a bunch of migrants. Available at http://www.huffingtonpost.co.uk/2016/02/02/refugees-incalais-explai_n_9138842.html (last access 13 November 2017).

VenUTI, L. 1992. Rethinking Translation: Discourse, Subjectivity, Ideology. London and New York: Routledge.

VIEIRA, E. R. P. 1992. 1994. A Postmodern Translational Aesthetics in Brazil in M. Snell-Hornby, M.; Pöchhacker, F.; and Kaindl, K. (ed.) Translation Studies Reader: An Interdiscipline. Amsterdam: John Benjamins. 65-72.

VIEIRA, E. R. P. 1999. Liberating Calibans: Readings of antropofagia and Haraldo de Campos' poetics of transcreation. in S. Bassnett and H. Trivedi (ed.). Post-colonial Translation: Theory and Practice. London/New York: Routledge.

\section{Works of art}

Askavusa Collective. 2013. Porto M, 3 October. Available at $<$ https://askavusa.wordpress.com/con-gli-oggetti/> (last access 13 November 2017); 16 December 2014. Available at <https://portommaremediterraneomigrazionimilitarizzazione. wordpress.com/> (last access 13 November 2017). 
Cipolla, G. 2016. Odisseo Arriving Alone (Permanent Exhibition. Paintings and Pictures) 16 December. Itastra, Complesso Sant'Antonino. Palermo.

FEDDA, Y. 2014. Queens of Syria. documentary film, Amman (Jordan). Refuge Productions.

LAFFERTY, Z. 2016. Queens of Syria. theatrical performance, Amman (Jordan), UK, Developing Artists, Refuge Productions and Young Vic co-production.

JARALLA, Y. L. 2016. Odisseo Arriving Alone (performance), with D. Bandidugou \& A. Diallu, and the students from Liceo classico Vittorio Emanuele II, Itastra, Complesso Sant'Antonino, Palermo, 16 December.

McElvaneY, K. 2015. Project \#RefugeeCameras. Available at $<$ http://kevin-mcelvaney.com/portfolio/projectrefugeecameras/>. Photo-textual exhibition, second edition of the Festival of Migrant Literatures, Palermo, Italy, GAM (12 October 2016). 